\title{
Acidic Reaction of Waste Aluminum Foil for Alumina Production
}

\author{
S.T. El Sheltawy, N.F. Abdel Salam*, F.I. Barakat \\ Cairo University, Faculty of Engineering, Chemical Engineering Department, Giza, Egypt.
}

\section{AR T I C LEDETAILS}

\section{Article history:}

Received 05 March 2019

Accepted 18 March 2019

Available online 03 April 2019

\section{Keywords:}

Alumina

Factorial Design

Waste Removal

\begin{abstract}
A B S T R A C T
Batch experiments were performed in order to evaluate the most effective conditions of reaction between aluminum foil waste and hydrochloric acid using a statistical model based on $2^{3}$ full factorial design. The three factors investigated were aluminum foil waste particle size, aluminum foil to acid solution ratio, and acid solution concentration. The optimization of the factors to obtain maximum conversion was carried out by incorporating surface plots. A first order model was elaborated and indicated that the maximum observed conversion reaches $97.6 \%$ compared with $95.69 \%$ calculated conversion under the following conditions: solid to liquid ratio of $0.0127 \mathrm{~g}$ foil $/ \mathrm{g} \mathrm{HCl}$ solution, aluminum foil particle size of $10 \mathrm{~mm}$ and $2 \mathrm{M}$ acid concentration. XRF showed that the obtained alumina has a purity of $90.13 \%$ by weight.
\end{abstract}

\section{Introduction}

The first commercial production of aluminum foil started in the United States by 1913 where it was used for wrapping life savers, candy bars, and similar items. Aluminum foil is usually produced as a thin-rolled sheet of alloyed aluminum varying in thickness from about $4-150 \mu \mathrm{m}$. Its uses developed from paperboard in 1921 to household foil then to heat sealable foil to reach formed, semi-rigid, containers by mid twentieth century [1]. One main reason for its expanded uses is the extremely low permeability of foils of thickness above $15 \mu \mathrm{m}$ which is way lower than that of most food packaging plastic films [2].

On the other hand, aluminum is produced worldwide mainly through bauxite ores. This production increased from 183 million metric tons in 2006 to reach $270 \mathrm{Mt}$ in 2015 . On the other hand, the aluminum US consumption also increased through the same period from $45 \mathrm{Mt}$ to $20 \mathrm{Mt}$ with a growth rate of about $4 \%$ per year. Most of the metal is produced by the Bayer process essentially involving the action of an alkaline solution on bauxite. The problem with that process is the huge amount of energy involved (14 MWh per ton) and the formation of numerous environmentally unfriendly wastes such as tailings, red mud besides gaseous emissions of perfluorocarbon, and $\mathrm{CO}_{2}[3,4]$.

It appears therefore that recycling of aluminum waste can represent a sustainable solution for the environmental issue. It has been reported that recycling of 1 ton of aluminum saves 8 tons of bauxite, 4 tons of chemical products besides $14 \mathrm{MW}$ of electricity [4]. Owing to the fact that the Egyptian territory contains very limited bauxite reserves [5]. It was necessary to find other routes for producing alumina $\left(\mathrm{Al}_{2} \mathrm{O}_{3}\right)$ which is mainly known for its use in the production of Aluminum, and employed in many other applications like glass industry, water purification, refractory materials and ceramics [6].

Although converting aluminum foil into useful products is an important environmental issue as mentioned above, the studies performed in this research area are limited [7]. Recently, Visbal et al used Al foil waste in hydrogen production by converting it into active $\mathrm{Al}$ powder that reacts with water or by using $\mathrm{Ca}(\mathrm{OH})_{2}$ to remove the surface oxide layer and initiate the hydration reaction [8].

El Amir et al [9] prepared nanoscale single crystalline $\Upsilon$-Alumina powder from aluminum foil waste precursor via co-precipitation method using Ammonium Hydroxide $\mathrm{NH}_{4} \mathrm{OH}$ as a precipitant, while Osman et al [10] prepared alumina from aluminum foil scrap using $6 \mathrm{M}$ hydrochloric acid solution to form aluminum Chloride solution from which the

hydroxide was precipitated using ammonia solution. The pale off-white precipitate was then filtered, washed, dried at $120{ }^{\circ} \mathrm{C}$ and calcined at 550 ${ }^{\circ} \mathrm{C}$ for 4 hours in a muffle furnace. This work however stopped short of investigating the effect of the parameters affecting the dissolution reaction.

The present work aims at using a statistical approach, namely the factorial design technique to determine the most effective conditions for alumina recovery from aluminum foil waste reaction with hydrochloric acid. This technique has been successfully used in several industrial applications. The effect of the following variables on alumina recovery has been investigated: Acid concentration, foil particle size, and acid to foil ratio.

\section{Experimental Methods}

\subsection{Materials}

The raw materials used in this study were aluminum foil waste packages collected from home use, hydrochloric acid (37\%) analytical grade, and ammonium hydroxide $\mathrm{NH}_{4} \mathrm{OH}(25 \%)$ supplied by ElGomhoreya Co., Cairo, Egypt.

\subsection{Experimental Work}

First the used foil packages were washed, and cut to the required size using a rotary knives cutter. The required amount of $\mathrm{HCl}$ was then added to the stoichiometric amount of $\mathrm{Al}$ foil, and the reaction allowed to occur for 5 minutes through the following rapid exothermic corrosion reaction:

$$
\mathrm{Al}+6 \mathrm{HCl} \rightarrow 2 \mathrm{AlCl}_{3}+3 \mathrm{H}_{2} \quad \Delta \mathrm{H}=-527.5 \mathrm{~kJ} / \mathrm{mol} .
$$

The suspension was immediately filtered using a glass filter to separate unreacted materials. Aluminum chloride solution was obtained as filtrate. Ammonium hydroxide solution (25\%) was then added to the filtrate drop wise until the $\mathrm{pH}$ reached 10 resulting in precipitation of $\mathrm{Al}(\mathrm{OH})_{3}$ by the following reaction:

$$
\mathrm{AlCl}_{3}+\mathrm{NH}_{4} \mathrm{OH} \rightarrow \mathrm{A}(\mathrm{OH})_{3}+3 \mathrm{NH}_{4} \mathrm{Cl}
$$

The gelatinous precipitate formed was separated from the solution using filter paper, dried in for one hour at a temperature of $250{ }^{\circ} \mathrm{C}$, and finally was calcined at $600{ }^{\circ} \mathrm{C}$ for one hour in a laboratory muffle furnace to produce alumina as follows:

$2 \mathrm{~A}(\mathrm{OH})_{3} \rightarrow \mathrm{Al}_{2} \mathrm{O}_{3}+3 \mathrm{H}_{2}$ 


\subsection{The Factorial Design}

The high and low levels defined for the $2^{3}$ factorial design are listed in Table 1 . The choice of the low and high levels for the factors was made according to the following criteria: Acid to foil ratio was chosen to keep suitable fluidity of the resulting mixture whereas the particle size range was tentatively selected according to common practice figures used in recycling.

Table 1 Experimental ranges of investigated independent variables

\begin{tabular}{lllll}
\hline Variable & Symbol & Unit & Lower level & Higher level \\
\hline Solid to liquid ratio & $X_{1}$ & $\mathrm{~g} / \mathrm{g}$ & 0.0127 & 0.0153 \\
Particle size & $X_{2}$ & $\mathrm{~mm}$ & 10 & 3 \\
Acid concentration & $X_{3}$ & $\mathrm{M}$ & 2 & 6 \\
\hline
\end{tabular}

The conditions of the conducted experiments can be summarized in the following Table 2 .

Table 2 The experimental conditions

\begin{tabular}{llll}
\hline Exp. No. & S/L Ratio & Particle Size $(\mathrm{mm})$ & Acid Conc. $(\mathrm{M})$ \\
\hline 1 & 0.0127 & 10 & 2 \\
2 & 0.0153 & 10 & 2 \\
3 & 0.0127 & 30 & 2 \\
4 & 0.0153 & 30 & 2 \\
5 & 0.0127 & 10 & 6 \\
6 & 0.0153 & 10 & 6 \\
7 & 0.0127 & 30 & 6 \\
8 & 0.0153 & 30 & 6
\end{tabular}

Three replicate experiments were performed at the center of design at $\mathrm{S} / \mathrm{L}$ ratio of 0.014 , particle size of $20 \mathrm{~mm}$, and acid ratio of $4 \mathrm{M}$.

\section{Results and Discussion}

\subsection{Factorial Design Calculations}

The application of orthogonal factorial design technique involves the following steps $[11,12]$.

Coded variables are next defined for each of the three-parameter investigated so as to obtain $-1,+1$ or 0 values for minimum, central, and maximum levels respectively as indicated in Table 3.

Table 3 Coded variables

\begin{tabular}{llc}
\hline Variable & Symbol & Coded symbol, $X$ \\
\hline Solid to liquid ratio & $S / L$ & $\frac{(S / L)-0.014}{0.0013}$ \\
Particle size & $D_{\mathrm{p}}$ & $\frac{D_{p}-20}{10}$ \\
Acid concentration & $C$ & $\frac{C-4}{2}$ \\
\hline
\end{tabular}

Table 4 Coded matrix

\begin{tabular}{llllllll}
\hline$X_{0}$ & $X_{1}$ & $X_{2}$ & $X_{3}$ & $X_{1} X_{2}$ & $X_{2} X_{3}$ & $X_{3} X_{1}$ & $X_{1} X_{2} X_{3}$ \\
\hline 1 & -1 & -1 & -1 & 1 & 1 & 1 & -1 \\
1 & 1 & -1 & -1 & -1 & 1 & -1 & 1 \\
1 & -1 & 1 & -1 & -1 & -1 & 1 & 1 \\
1 & 1 & 1 & -1 & 1 & -1 & -1 & -1 \\
1 & -1 & -1 & 1 & 1 & -1 & -1 & 1 \\
1 & 1 & -1 & 1 & -1 & -1 & 1 & -1 \\
1 & -1 & 1 & 1 & -1 & 1 & -1 & -1 \\
1 & 1 & 1 & 1 & 1 & 1 & 1 & 1 \\
1 & 0 & 0 & 0 & 0 & 0 & 0 & 0 \\
1 & 0 & 0 & 0 & 0 & 0 & 0 & 0 \\
1 & 0 & 0 & 0 & 0 & 0 & 0 & 0 \\
\hline
\end{tabular}

A design matrix $M$ is then established involving $2^{3}$ combinations of -1 , and +1 values of the 3 variables. The alumina recovery for all 8 experimental conditions is then measured, and a column vector $Y$ (Conversion) is obtained. In first order design the regression equation for coded variables takes the form:

$$
\begin{gathered}
y=a_{0}+\sum_{1=1}^{5} a_{i} x_{i}+\sum_{i=1, j=1, i \neq j}^{5} a_{i j} x_{i} x_{j}+\sum_{i \neq j \neq k}^{5} a_{i j k} x_{i} x_{j} x_{k}+ \\
\sum_{i \neq j \neq k \neq 1}^{5} a_{i j k l} x_{i} x_{j} x_{k} x_{l}+a_{12345} x_{1} x_{2} x_{3} x_{4} x_{5}
\end{gathered}
$$

This equation contains 8 constants corresponding to a coefficient column vector A. The value of the elements of vector A can be obtained from the Eq.(5),

https://doi.org/10.30799/jespr.163.19050104

$$
\mathrm{A}=\mathrm{M}^{-1} \cdot \mathrm{Y}
$$

where, $M$ represents the following $8 \times 8$ matrix including the coded variables defined by Table 3 and $\mathrm{Y}$ is the column vector consisting of the results of reaction yield of the 8 runs.

11 experimental runs were performed at the conditions specified in Table 5 involving three replicates at the center point of design. The values of the coefficients in the coded regression Eq.(4) could then be obtained by applying Eq.(5).

After applying the $t$ - test, some of the coefficients were eliminated for being statistically insignificant. When the coded variables then replaced by original variables according to their definition in Table 3, the following regression equation was obtained for percent conversion,

$$
\text { Conversion }(\mathrm{Y})=290.14-13715.39 S / L-4.42 D_{\mathrm{p}}-18.5 C+272.46
$$$$
(S / L) \cdot D_{p}+0.1538 D_{p} \cdot C+1107.31(S / L) \cdot C
$$

Once the regression equation has been established and non-significant coefficients eliminated, the validity of the expression can be tested by calculating the determination coefficient $\mathrm{R}^{2}$ which was found to be 0.9548 , meaning that $95.48 \%$ of the variation in conversion is due to the variations in the three parameters.

Table 5 Design conditions, and observed alumina recovery (first order model)

\begin{tabular}{llllllll}
\hline Run & $S / L$ & $X_{1}$ & $D_{p}$ & $X_{2}$ & $C$ & $X_{3}$ & Y (observed) \\
\hline 1 & 0.0127 & -1 & 10 & -1 & 2 & -1 & 97.64 \\
2 & 0.0153 & +1 & 10 & -1 & 2 & -1 & 73.53 \\
3 & 0.0127 & -1 & 30 & +1 & 2 & -1 & 79.41 \\
4 & 0.0153 & +1 & 30 & +1 & 2 & -1 & 72.06 \\
5 & 0.0127 & -1 & 10 & -1 & 6 & +1 & 74.12 \\
6 & 0.0153 & +1 & 10 & -1 & 6 & +1 & 64.12 \\
7 & 0.0127 & -1 & 30 & +1 & 6 & +1 & 70.78 \\
8 & 0.0153 & +1 & 30 & +1 & 6 & +1 & 72.35 \\
9 & 0.014 & 0 & 20 & 0 & 4 & 0 & 88.05 \\
10 & 0.014 & 0 & 20 & 0 & 4 & 0 & 86.70 \\
11 & 0.014 & 0 & 20 & 0 & 4 & 0 & 89.67 \\
\hline
\end{tabular}

The observed conversions were compared with the conversions calculated from the deduced regression equation. The results can be summarized in Fig. 1 which reveals excellent concordance between the two sets of values.

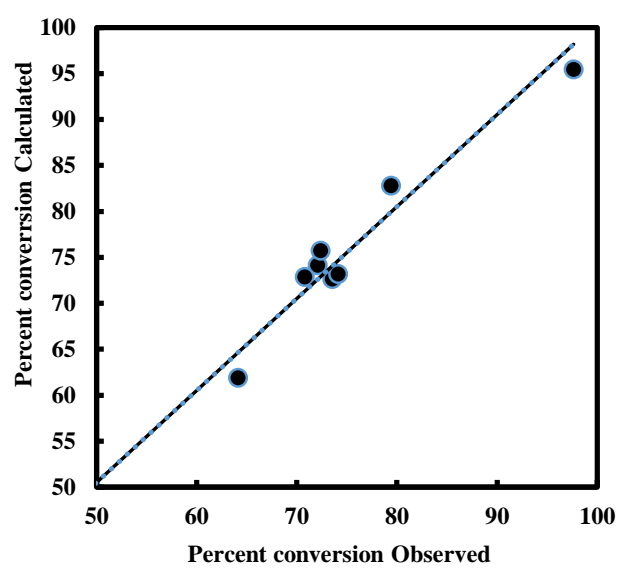

Fig. 1 Observed conversion versus predicted conversion

\subsection{Surface Plots}

These plots can be obtained by computations using developed response models and adequate software (XLSTAT free trial). From Fig. 2, we can observe that the conversion decreased as the $\mathrm{S} / \mathrm{L}$ ratio increased as could also be deduced from the negative coefficient obtained in Eq.(6). This is since when solid to liquid ratio was increased, the amount of aluminum solid per unit liquid increased causing a decrease in recovery [13]. The same trend can be observed at acid concentration of $4 \mathrm{M}$ and $6 \mathrm{M}$.

Also, from Fig. 3, it can be observed that the conversion increased as the particle size decreased. That can be explained by the increased surface area exposed to the reaction.

From Fig. 4, it can also be observed that: the conversion decreased as the acid concentration increased. This can be explained by the formation of an oxide passive layer on the surface of aluminum. The aluminum oxide layer is chemically bound to the surface and seals the core aluminum from any further reaction [14]. 


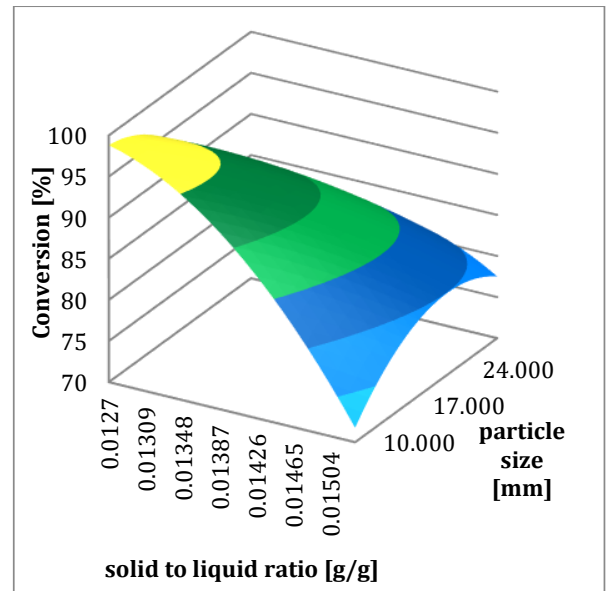

Fig. 2 The effect of S/L Ratio on the conversion and particle size at $2 \mathrm{M}$ acid concentration

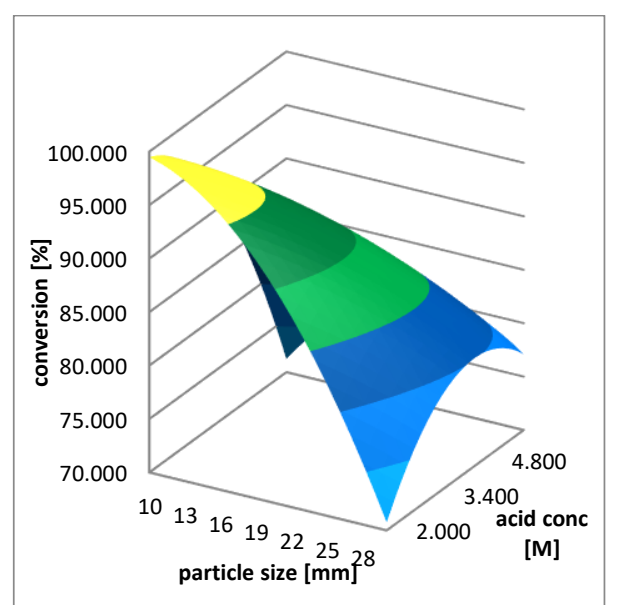

Fig. 3 The effect of particle size and acid concentration on the conversion at S/L ratio $=0.0127$

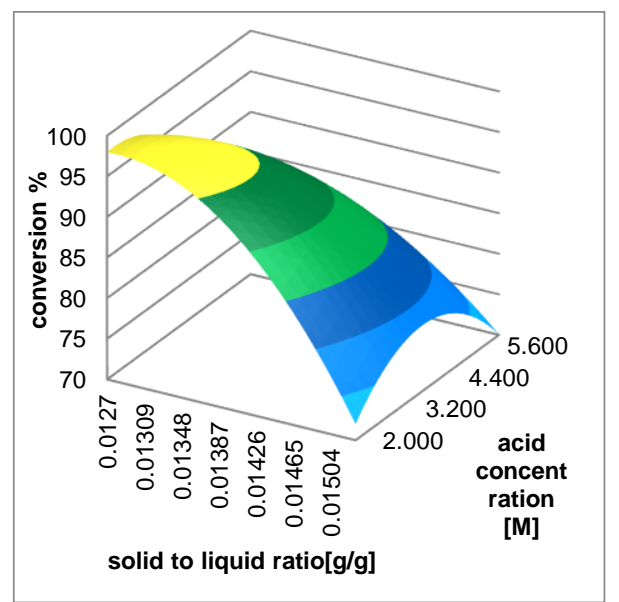

Fig. 4 The effect of solid to liquid ratio and acid concentration on the conversion at particle size of $1 \mathrm{~cm}$

The experimentally prepared Alumina was analyzed using Axios advanced, Sequential WD_XRF Spectrophotometer, and the result was as follows in Table 6.
Table 6 Produced alumina analysis

\begin{tabular}{ll}
\hline Main Constituents & g/g (mass\%) \\
\hline $\mathrm{SiO}_{2}$ & 0.45 \\
$\mathrm{TiO}_{2}$ & 0.02 \\
$\mathrm{Al}_{2} \mathrm{O}_{3}$ & 90.13 \\
$\mathrm{Fe}_{2} \mathrm{O}_{3}$ tot. & 0.63 \\
$\mathrm{CaO}$ & 0.09 \\
$\mathrm{Na}_{2} \mathrm{O}$ & 0.04 \\
$\mathrm{~K}_{2} \mathrm{O}$ & 0.01 \\
$\mathrm{SO}_{3}$ & 0.04 \\
$\mathrm{Cl}$ & 3.13 \\
$\mathrm{LOI}$ & 5.39 \\
$\mathrm{MnO}$ & 0.006 \\
$\mathrm{NiO}$ & 0.024 \\
$\mathrm{CuO}$ & 0.014 \\
$\mathrm{ZnO}$ & 0.005 \\
$\mathrm{Ga}_{2} \mathrm{O}_{3}$ & 0.016 \\
\hline
\end{tabular}

\section{Conclusion}

$2^{3}$ Full factorial design was used to assess the best conditions for alumina recovery from aluminum foil waste by reaction with hydrochloric acid. The investigated parameters were: solid to liquid ratio, foil particle size, and acid concentration. A first order model was first elaborated, and a regression equation obtained that showed a strong determination coefficient (0.9548). The maximum observed conversion reaches $97.6 \%$ compared with $95.7 \%$ calculated conversion under the following conditions: solid to liquid ratio of $0.0127 \mathrm{~g}$ foil/g $\mathrm{HCl}$ solution, aluminum foil particle size of $1 \mathrm{~cm}$, and $2 \mathrm{M}$ acid concentration. XRF showed that the obtained alumina has a purity of $90.13 \mathrm{~g} / \mathrm{g}$ (mass \%).

\section{References}

[1] G.L. Robertson, Food packaging: principles and practice, $3^{\text {rd }}$ Edn., Taylor \& Francis, Boca Raton, 2013.

[2] M. Lamberti, F. Escher, Aluminium foil as a food packaging material in comparison with other materials, Food Rev. Int. 23(4) (2007) 407-433.

[3] W.D. Menzie, J.J. Barry, D.I. Bleiwas, E.L. Bray, T.G. Goonan, G. Matos, The global flow of aluminum from 2006 through 2025, U.S. Geological Survey, 2010.

[4] I.B. Frenkel, A. Karagrigoriou, A. Lisnianski, A.V. Kleyner, Applied reliability engineering and risk analysis: probabilistic models and statistical inference, $1^{\text {st }}$ Edn., John Wiley \& Sons Ltd, United Kingdom, 2014.

[5] A.M. Amer, Hydrometallurgical processing of egyptian bauxite, Physico. chem. Miner. Process 49(1) (2013) 431-442.

[6] L.K. Hudson, C. Misra, A.J. Perrotta, K. Wefers, F.S. Williams, Ullmann's encyclopedia of industrial chemistry, 6 $6^{\text {th }}$ Edn., Wiley-VCH, Weinheim, 2002.

[7] A.K. Narayana Swamy, E. Shafirovich, Conversion of aluminum foil to powders that react and burn with water, Combust. Flame 161 (2014) 322-331.

[8] H. Visbal, K. Nagashima, K. Hirao, Surface analysis of three aluminum foils and relation to hydrogen generation capability, Korean J. Chem. Eng. 33(4) (2016) 1255-1260.

[9] A.A.M. El-Amir, E.M.M. Ewais, A.R. Abdel-Aziem, A. Ahmed, B.E.H. El-Anadouli, Nano-alumina powders/ceramics derived from aluminum foil waste at low temperature for various industrial applications, J. Environ. Manag. 183 (2016) 121-125.

[10] A.I. Osman, J.K. Abu-Dahrieh, M. McLaren, F. Laffir, P. Nockemann, D. Rooney, A facile green synthetic route for the preparation of highly active $\gamma-\mathrm{Al}_{2} \mathrm{O}_{3}$ from aluminum foil waste, Sci. Rep. 7 (2017) 3593-3604.

[11] S. Akhnazarova, V. Kafarov, Experiment optimization in chemistry and chemical engineering, 2nd Edn., Mir Publishers, Moscow, 1982.

[12] F. Hoang, Springer Handbook of Engineering Statistics, $1^{\text {st }}$ Edn., SpringerVerlag, 2006.

[13] I. Mehdi, M. Mohammad, A. Amir Reza, Leaching of zinc from low grade oxide ore using organic acid, Physicochem. Prob. Miner. Proces. 49 (2013) 547-555.

[14] S. Attavar, M. Diwekar, M.R. Linford, M.A. Davis, S. Blair, Passivation of aluminum with alkyl phosphonic acids for biochip applications, Appl. Surf. Sci. $256(2010) 7146-7150$. 